\title{
Medication and Sudden Cardiac Death. Unexpected Risks!
}

\section{Rosa Henriques de Gouveia ${ }^{* *}$, José Carvalho², Paula Monsanto ${ }^{3}$ and João Pinheiro ${ }^{4}$}

${ }^{1}$ Forensic Pathology Department, Delegação do Centro, Instituto Nacional de Medicina Legal e Ciências Forenses, I.P. and Pathology Professor, Medical Faculty, Coimbra University, Coimbra, Portugal

${ }^{2}$ Forensic Pathology Department, Delegação do Centro - Azores Extention, Instituto Nacional de Medicina Legal e Ciências Forenses, I.P., Azores, Portugal

${ }^{3}$ Forensic Toxicology and Chemistry Department, Delegação do Centro, Instituto Nacional de Medicina Legal e Ciências Forenses, I.P., Coimbra, Portugal

${ }^{4}$ Forensic Pathology Department, Delegação do Centro, Instituto Nacional de Medicina Legal e Ciências Forenses, I.P., Coimbra, Portugal

\begin{abstract}
The authors report the case of a 33-year-old male on medication for an upper respiratory tract infection, who, when in a public place with his friends, died sudden and unexpectedly. Post-mortem examination revealed a "Mixed Cellularity (Eosinophilic-rich) Acute Myocarditis", most likely due to drug hypersensitivity. In an era of broad and increasing therapeutic drugs use, the case draws attention to the risk of medication underlying Sudden Cardiac Death.
\end{abstract}

Keywords: Medication; Hypersensitivity; Myocarditis; Sudden cardiac death; Young; Autopsy; Histopathology; Toxicology

\section{Introduction}

Sudden Cardiac Death (SCD) is defined as "a natural, unexpected fatal event, with a cardiac underlying cause, occurring instantly or within $1 \mathrm{~h}$ from the onset of symptoms in an apparently healthy subject or whose disease was not so severe as to predict an abrupt outcome" [1]. When not witnessed, it is assumed sudden if "the deceased was in good health $24 \mathrm{~h}$ before death" [1]. The overall incidence in the young (persons aged 1-35 years) is difficult to estimate, but some studies point to $7 \%$ [2]. In series where autopsies were performed to young sudden death victims, cardiac cause accounted for $67 \%$ to $79.3 \%[2,3]$. Among the various cardiovascular diseases, myocarditis occupies an important causal place in this age group. In fact, it is pointed as being responsible for 3.5\% of out-of hospital cardiac arrests [4] and having a greatly variable autopsy prevalence, such as $4 \%$ in the United Kingdom [5], 5.7\% in another series [3] and $2 \%$ to $42 \%$ in others [6]. World Health Organization / International Society and Federation of Cardiology (WHO / ISFC) define Myocarditis as "inflammatory disease of the myocardium diagnosed by established histological, immunological and immunohistochemical criteria." [6]. It may be classified using diverse characteristics/systems, namely the type of inflammatory cells (lymphocytes, eosinophils, neutrophils, other) or the underlying aetiology (infectious, autoimmune, drug toxicity, hypersensitivity, other) [6]. Quite often, the different classification systems correlate, favouring a specific diagnosis, like, for example, mixed cellularity/eosinophilic myocarditis and drug administration. Therapeutic drugs are a broad and challenging field inside myocarditis, due to the increasing number of new pharmaceutical products, the complexity of medical prescriptions and the self-medication, which may cause symptomatic or silent, progressive and disabling or fulminant myocarditis [6-8]. The authors report and discuss a case where medication-related myocarditis caused unexpected sudden death of cardiac aetiology in a young adult.

\section{Case Report}

\section{History}

A 33-year-old male, with no relevant personal or familial pathologic antecedents (including food or other substances known allergy) and no addiction habits, had begun ambulatory treatment for an occasional upper respiratory infection with amoxicillin / clavulanic acid (875 mg / $125 \mathrm{mg}, 2$ pills/day), ibuprofen ( $400 \mathrm{mg}, 2$ to 4 pills/day) and antigrippine $(250 \mathrm{mg} / 30 \mathrm{mg} / 20 \mathrm{mg}$, 4 pills/day). He was in a public place with his friends, when he lost consciousness. Cardiopulmonary resuscitation was unsuccessful; death being declared within 1h. A complete postmortem examination was performed.

\section{Autopsy findings}

Body of a young male with normal height and weight for age and gender. External Habitus examination showed no traumatic or other significant lesions. Internal Habitus examination revealed bilateral lung oedema plus generalized and severe vascular congestion of tissues and organs, leading to increased weight of left $(960 \mathrm{~g})$ and right $(980$ g) lungs and of the liver (2000 g). The heart presented normal weight (370 g), shape and dimensions, without malformations or macroscopic lesions. Organ samples were procured for microscopic examination. They were fixed in $10 \%$ formalin and embedded in paraffin. Microtome sections were stained with haematoxylin/eosin (H/E). Additional special stains (Masson Trichrome, Elastic van Gieson) were performed on the heart samples, for better interpretation. Photography of the histological slides was done using LEICA DM1000 LED microscope and image acquisition system LEICA ICC50 HD camera plus LAS EZ v2.0.0 for Windows software. Histopathological evaluation confirmed the severe and diffuse pulmonary oedema, as well as the generalized vascular congestion of all the organs. Unexpectedly, it revealed heart lesions, that consisted in diffuse myocardial inflammatory infiltrate, mainly localized in the interstitium, but inducing focal myocyte necrosis (Figure 1). The inflammatory infiltrate is polymorphic/ pleomorphic, gathering lymphocytes, histiocytes, eosinophils and mast cells. The eosinophils are present in high quantity; and both eosinophils and mast cells show degranulation (Figure 2). Toxicological tests

*Corresponding author: Rosa Henriques de Gouveia, Forensic Pathology Department, Delegação do Centro, Instituto Nacional de Medicina Legal e Ciências Forenses, I.P., Largo da Sé Nova 3000-213, Coimbra, Portugal, Tel: +351962685650; E-mail: rhgouveia@mail.telepac.pt

Received July 21, 2015; Accepted August 07, 2015; Published August 16, 2015

Citation: Gouveia RH, Carvalho J, Monsanto P, Pinheiro J (2015) Medication and Sudden Cardiac Death. Unexpected Risks!. Cardiol Pharmacol 4: 151. doi:10.4172/2329-6607.1000151

Copyright: (c) 2015 Gouveia RH et al. This is an open-access article distributed under the terms of the Creative Commons Attribution License, which permits unrestricted use, distribution, and reproduction in any medium, provided the original author and source are credited. 


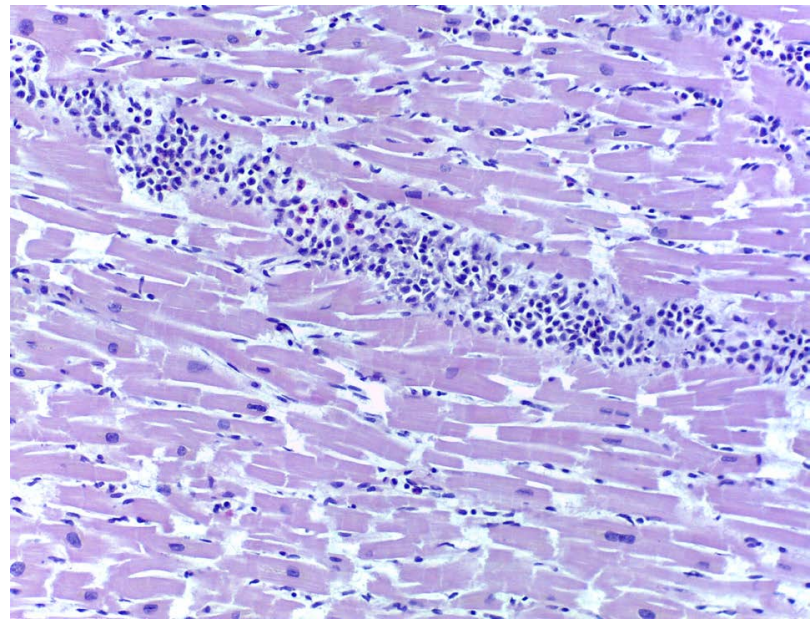

Figure 1: Histopathologic features of "Drug Hypersensitivity Mixed Cellularity (eosinophilic-rich) Myocarditis". View of the left ventricle myocardium with inflammatory infiltrates. These are interstitial, with focal myocyte damage/ necrosis. The inflammatory infiltrates contain cells of different types (lymphocytes, histiocytes, mast cells and polymorphonuclear), but are rich in eosinophils [H/E x100] (source: INMLCF,I.P.).

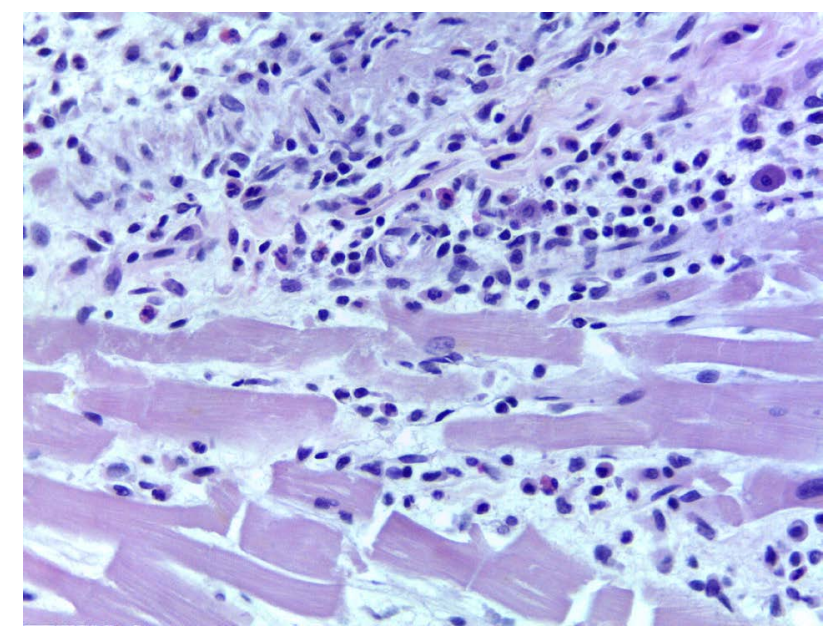

Figure 2: High magnification to better show myocyte damage/necrosis, the inflammatory cells and mast cells and eosinophils degranulation [H/E x400] (source: INMLCF,I.P.).

in the blood, from the heart and femoral vein, were negative for alcohol, drugs, medication and pesticides. The final diagnosis was that of a "natural cause of death, sudden and unexpected, due to Mixed Cellularity (eosinophil-rich) Acute Myocarditis of highly probable drug hypersensitive aetiology".

\section{Epidemiological context}

This case was the only one found in a series of 1141 autopsies performed during one year (2011) in a Medico-Legal Institution that serves a territorial area of $29.206 \mathrm{Km}^{2}$ with a population of 2.595 .540 inhabitants. Thus, in 2011, myocarditis was assumed to be responsible for $0.09 \%$ Sudden Cardiac Deaths in young persons of the deceased population, submitted to forensic postmortem examination, in that national territory.

\section{Discussion and Conclusion}

The presence of inflammatory cells on the myocardium should neither be overdiagnosed as myocarditis nor underestimated and seen as bystanders, missing the diagnosis. This may be accomplished performing the anatomo-pathological examination by a cardiovascular specialist [5]. Upper respiratory infection, directly or complicated by infectious (viral, bacterial) myocarditis, may cause sudden death. Yet, the cell types of the inflammatory infiltrates in the case reported point to / favour another cause. Mixed cellularity eosinophil-rich myocarditis / eosinophilic myocarditis may have a favourable clinical course, evolve to chronic heart failure or rapidly result in a fatality [9]. In autopsy studies, esteemed incidence ranges from $0.5 \%$ to $4 \%$ $[9,10]$. It may occur in different settings, like Systemic Eosinophilia, Idiopathic Hypereosinophilic Syndromes, Parasite Infections and Drug Hypersensitivity [9]. Technico-scientific progress and social / public health welfare increased therapeutic drugs availability, creating a new healthcare problem with Legal relevance, due to eventual malpractice suspicion. Despite pharmaceutical companies and medical / health practitioners warnings concerning medication side-effects and adverse reactions, this is a "swampy field" with unknown and unpredictable risks and outcomes. The following questions are still relevant and updated: 1) Does a certain drug per se induce hypersensitivity reactions? 2) Does it cause hypersensitivity in one person / group of persons but not in other, due to their pharmacogenomics and pharmacokinetics / pharmacodynamics? 3) Which is the target organ(s) of the hypersensitivity reaction? 4) Does polymedication cause or potentiate hypersensitivity risk? Are there cross-reactions and which? 5 ) Which is the real influence of each drug involved? Which is/are the culprit one(s)? 6) Are trace amounts of drugs, detected on chemical / toxicological analysis, mere bystanders or do they have noxious effect(s)? [11]. 7) How to reason when hypersensitivity reactions and/ or fatalities occur, despite negative chemical / toxicological tests? 8) Do environment factors (temperature, dehydration, ingestion of beverages or food, physical stress, other) precipitate hypersensitive reactions not otherwise predicted? In our case, every drug and its components - (amoxicillin/clavulanic acid) amoxicillin trihydrate, a $\beta$-lactam antibiotic; potassium clavulanate, a $\beta$-lactamase inhibitor; (ibuprofen) isobutylphenylpropanoic acid, a nonsteroidal anti-inflammatory drug; (antigrippine) paracetamol or $\mathrm{N}$-acetyl-p-aminophenol, a cyclooxygenase (COX) inhibitor used as antipyretic; caffeine or 1,3,7-trimethylpurine-2,6-dione, a methylxanthine class psychoactive drug; mepyramine maleate, a histamine antagonist - is susceptible of causing hypersensitivity adverse effects, as advised by the National Authority for Medication and Health Products, I.P. (INFARMED, I.P.) [12]. Thus, it is not easy to point out the culprit substance as the most possible killer agent in the drug-cocktail the victim was on. The heart tropism, instead of the involvement of another organ, may not only depend upon each drug (some of which are described to have caused eosinophilic myocarditis, like for example amoxicillin [8]), but also on the victim's genetics and immune system. The type of myocarditis [6] and the negativity of the toxicological tests favour a hypersensitivity mechanism to a toxic one. The co-existence of all the drugs / compounds ingested may have potentiated each isolated contribution to the immune / inflammatory response, which seems to be a Type I Hypersensitivity (anaphylactic, allergic type), immunoglobulin E (IGE)mediated [13]. Mast cells degranulation and eosinophils recruitment - activation - stimulation - degranulation lead to the liberation of multiple substances (especially cationic proteins), which not only maintain the immune response, but also promote the myocarditis and tissue damage $[13,14]$. In this setting, the exitus letalis may occur due 
Citation: Gouveia RH, Carvalho J, Monsanto P, Pinheiro J (2015) Medication and Sudden Cardiac Death. Unexpected Risks!. Cardiol Pharmacol 4: 151. doi:10.4172/2329-6607.1000151

Page 3 of 3

to rhythm disturbances [15] or to myocardial function decrease and failure [16], contributing to the diffuse organ vascular congestion and severe lung oedema observed on postmortem examination. Since the victim was in a public place with his friends, temperature, physical effort (even if minor) and other eventual environment / circumstantial factors may have aggravated the clinical evolution.

Since these fatalities are mostly unpredictable, it is not easy to avoid them. Yet, the authors highlight some pivotal steps to minimize, as much as possible, such unexpected tragedies in the future:

1) When prescribing, always keep in mind the possibility of a hypersensitivity reaction.

2) Each health professional should be aware of the characteristics and side-effects of the medicines that usually prescribe.

3) Question the patient or the family about known allergic antecedents. When not possible, look for written notes, metallic plaques, etc that may accompany the patient.

4) Whenever possible, avoid polymedication.

5) Avoid overmedication.

6) Alert against self-medication.

7) Acquire the basic knowledge to act in face of a hypersensitivity reaction / emergency suspicion.

In conclusion, this work reinforces the need to a careful use of any kind of medication, since it may present as an iatrogenic cause of acute fulminant hypersensitivity myocarditis and an unexpected risk for sudden cardiac death.

\section{Acknowledgements}

To the Instituto Nacional de Medicina Legal e Ciências Forenses, I.P.

\section{Conflict of Interest Statement}

The authors declare no financial interests or other conflict of interest in relation to the work submitted.

\section{References}

1. Basso C, Burke M, Fornes P, Gallagher PJ, de Gouveia RH, et al. (2008) Guidelines for autopsy investigation of sudden cardiac death. Virchows Arch 452: 11-18.
2. Winkel BG, Holst AG, Theilade J, Kristensen IB, Thomsen JL, et al. (2011) Nationwide study of sudden cardiac death in persons aged 1-35 years. Eur Heart J 32: 983-990.

3. Eckart RE, Shry EA, Burke AP, McNear JA, Appel DA, et al. (2011) Sudden death in young adults: an autopsy-based series of a population undergoing active surveillance. J Am Coll Cardiol 58: 1254-1261.

4. Deasy C, Bray JE, Smith K, Harriss LR, Bernard SA, et al. (2011) Out-ofhospital cardiac arrests in young adults in Melbourne, Australia-adding coronial data to a cardiac arrest registry. Resuscitation 82: 1302-1306.

5. De Noronha SV, Behr ER, Papadakis M, Ohta-Ogo K, Banya W, et al. (2014) The importance of specialist cardiac histopathological examination in the investigation of young sudden cardiac deaths. Europace 16: 899-907.

6. Caforio AL, Pankuweit S, Arbustini E, Basso C, Gimeno-Blanes J, et al. (2013) Current state of knowledge on ætiology, diagnosis, management, and therapy of myocarditis: a position statement of the European Society of Cardiology Working Group on Myocardial and Pericardial Diseases. Eur Heart J 34: 26362648.

7. Fineschi V, Neri M, Riezzo I, Turillazzi E (2004) Sudden cardiac death due to hypersensitivity myocarditis during clozapine treatment. Int J Legal Med 118: 307-309.

8. Huston B, Froloff V, Mills K, McGee M (2013) Death due to eosinophilic necrotizing myocarditis despite steroid treatment. Am J Forensic Med Pathol 34: 95-97.

9. Sohn KH, Song WJ, Kim BK, Kang MK, Lee SY, et al. (2015) Eosinophilic myocarditis: case series and literature review. Asia Pac Allergy 5: 123-127.

10. Zhang M, Tavora F, Zhang Y, Ripple M, Fowler D, et al. (2013) The role of focal myocardial inflammation in sudden unexpected cardiac and noncardiac deaths--a clinicopathological study. Int J Legal Med 127: 131-138.

11. Henriques de Gouveia R, Paulo M, Dias MJ, Costa Santos F, Costa Santos J (2010) Sudden Cardiac Death - A Case With Two Distinct And Unrelated Causes. In: Vieira DN, Busuttil A, Cusack D, Beth P (eds) Acta Medicinæ Legalis et Socialis. (1stedn), Imprensa da Universidade de Coimbra, Coimbra.

12. http://www.infarmed.pt

13. Kumar V, Abbas A, Fausto N, Aster J (2010) Diseases of the Immune System Robbins and Cotran Pathologic Basis of Disease. (8thedn), Saunders Elsevier, Philadelphia.

14. Li H1, Dai Z, Wang B, Huang W (2015) A case report of eosinophilic myocarditis and a review of the relevant literature. BMC Cardiovasc Disord 15: 15.

15. Klein RM, Vester EG, Brehm MU, Dees H, Picard F, et al. (2000) [Inflammation of the myocardium as an arrhythmia trigger]. Z Kardiol 89 Suppl 3: 24-35.

16. Bhogal N, Grady AM, Ursell PC, Collins KK, Hornberger LK (2008) Hypersensitivity myocarditis presenting as atrioventricular block and wide complex tachycardia in a toddler. Congenit Heart Dis 3: 359-364. 